\title{
Evolving Trend of EVLP: Advancements and Emerging Pathways
}

\author{
Guohui Jiao $^{1}$ \\ Accepted: 17 January 2019 / Published online: 31 January 2019 \\ (C) Springer Nature Switzerland AG 2019
}

\begin{abstract}
Lung transplant augmentation in the waiting list is impeded by donor lung shortage with a low percentage of procurement. Ex vivo lung perfusion (EVLP) was recognized to have the capacity of providing a platform to preserve, assess, recondition, and even mange existing diseases in rejected donor lungs to expand the donor pool. This review aims to provide the most advanced experimental evidence of EVLP application and perspective as a platform providing qualified donor lungs. Literature review using PubMed, Medscape, Clinical Trials, and Cochrane databases was performed. Data was collected and analyzed. From a view point of publisher, current research centers with their paper contribution volume are also presented to illustrate the future trend of EVLP academically. EVLP incubated donor lungs could have a comparable outcome with conventional transplants. Further interventional studies have shown growing interest in and expectations on EVLP platform as pathways to determine graft quality, to bridge a critical phase of the initial rejected organs and to predict prognosis or complications in an early stage. EVLP is also considered as a tissue regeneration translational research environment with multidisciplinary potential to enhance the recovery and rehabilitation after surgery and advance pulmonary medicine. Ongoing clinical trials and accelerated procedure modulation with commercialization of EVLP are leading to "centralization" organ preparation model, opening a new era of lifechange health innovation.
\end{abstract}

Keywords EVLP $\cdot$ Transplant $\cdot$ Immune $\cdot$ Organ repair $\cdot$ Publication

Lung transplantation has been considered as the only therapeutic option for pulmonary failure. Donor lungs are harvested from only $15-20 \%$ compared with $30 \%$ of deceased donors for hearts [1]. However, it is estimated that up to $40 \%$ of rejected donor lungs may have been suitable for transplantation [2].

To overcome the acceptable donor lung pool shortage, ex vivo lung perfusion (EVLP) was recognized to have the capacity of providing a platform to preserve, assess, recondition, and even mange existing disease in rejected donor lungs to expand the donor pool. EVLP has contributed to an increase in transplantable lungs of at least $15-20 \%$ [3]. When reviewing all the multi-organ donors (MODs) from collaborative donor hospitals, lung donors are declined at $45.9 \%$,

This article is part of the Topical Collection on Medicine

\section{Guohui Jiao}

1 RM 408-409, Beijing Ideal Plaza No. 58 Northwest, 4th Ring Road, Haidian District, Beijing 100080, China
$21.4 \%$ of the declined lung is considered to become transplantable after EVLP [4].

According to the updated published data by ISHLT, 2018 [5], donor lung ischemic time ( $>5 \mathrm{~h})$ is among the risk factors for 1-year mortality. Transplant center volume is one of the continuous factors with statistical risk for long-term mortality, which may indicate that experienced surgeons or better condition of donor lungs will provide recipients a prospective prognosis.

\section{History of EVLP Technique Development}

Carrel and Lindbergh [6] described the initial draft of ex vivo organ perfusion in as early as 1935. In 1970, Jirsch and colleagues [7] introduced EVLP as a method to assess the quality of pulmonary grafts during storage prior to transplant using a canine model. When Hardesty tried to study normothermic EVLP in the 1980 s, unsatisfied outcome forced him to abandon the experiment [8]. Lund protocol was the first EVLP applied to evaluate lungs from cardiac death patient by Dr. Stig Steen from Lund, Sweden, 2001 [9]. Steen et al. further performed 
the recondition test on rejected lung successfully [10]. Cypel, Keshavjee, and colleagues in Toronto, Canada modified Dr. Steen's EVLP techniques, started the first clinical trial of EVLP, and reported excellent outcomes in 2011; this study had a major impact on lung transplant community [11].

In some countries where marginal lungs are being used, such as from ECMO donors, severe infected donors as well as controlled (cDCD) and uncontrolled ( $\mathrm{UDCD}$ ) donors, EVLP is increasingly applicable in critical conditions, while long-distance transportation may further call for the use of portable device of lung perfusion $[12,13]$. However, balance of expanding pool, prolonging graft function, and medical cost should be maintained and kept revising.

\section{Primary Benefit of EVLP on Donor Lungs}

EVLP has been recognized as a part of the general clinical practice in Europe and USA, by improving the usage of marginal lungs. In recent years, EVLP has been considered as a platform for moderating the organ acceptability in the way of: molecular diagnosis for changing the quality of donor lungs and organ repair for allowing more use [14]. Although up to now, most results have been reported from animal models or rejected human lungs, the prospect we have met will lead us to explore more approach in clinical use.

Evidence has accumulated to further explore the beneficial effect which ELVP could bring up, such as mortality, hospital stay, and rates of primary graft dysfunction, at least reaching the same potency as conventional lung transplants [15]. Further, according to the common evaluation system of lung transplant recipient outcome, the need for cardiopulmonary extracorporeal membrane oxygenation on ventilation, in ICU, and in-hospital stay, 30-day, 1-year, and 5-10-year survival rates, respectively; rates of acute rejection and chronic lung allograft dysfunction; and peak and 12-month lung function will be needed to demonstrate the role of EVLP performing in the whole process. EVLP is applied as a strategy of perioperative lung donor evaluation and intervention to consider using marginal lungs to pursue promising results [16].

\section{Early Human Reports with Long-Term Follow-Up of EVLP Incubated Lungs}

It was from 2014 that reports on donor lungs after EVLP used for transplantation came to be published. Experiences were exclusively from Europe and North America (Table 1). Ratio of lung acceptance, physiological data, and critical care requirement were the main index to compare and follow-up. During the relative long-term observation, acute rejection and chronic rejection, together with 1-year and 5-year survival rates were discovered, but not fully presented.

Earlier, Denmark's experience roughly showed that rejected marginal donor lungs could bring the recipients alive with normal graft function at the end of registration period [26]. An Italy report was one of the earliest cohort studies concentrating on primary graft dysfunction (PGD) occurrence. Rate of PGD 3 in EVLP-incubated lungs and conventional lungs was similar, while all EVLP patients suffering from severe PGD early after transplant recovered with normal lung function at $72 \mathrm{~h}$ [17]. This brought enormous hope for the recipients and transplant surgeons.

Single center from Toronto reported 403 lung transplants with $15.6 \%$ EVLP-assistance, until 5-year analyzing, no difference has been shown on survival, freedom from CLAD and functional outcomes [19]. Another 32 rejected donor lungs after EVLP and were used to do transplantation surgery, comparing to those transplant lungs without EVLP, there was no difference in extubation time, intensive care unit stay length, PGD rate, and 1-year survival rate. Further, 4-year cumulative survival, freedom from retransplantation, and chronic rejection rate were still comparable [20]. It thus concluded that EVLP could assist more high-risk donor lungs rather than conventionally selected donor lungs.

After evaluating the primary comparable efficiency of EVLP on marginal or rejected donor lungs, more focus was applied to the post-surgery lung function with physiological parameters and functional outcomes. Data from the University of Alberta [21] showed that $64 \%$ DCD lung transplant underwent portable EVLP, with a significantly shorter cold ischemic time and lower grade of primary graft dysfunction; there was no difference between the groups on mechanical ventilation time, hospital length of stay, functional outcomes, and life quality at 1 -year follow-up. During the 3-months and 6-months follow-up, FEV1\%, FVC\%, FEV1/FVC, 6MWT distance, and Borg dyspnea score were further compared with significant difference. A report from Brazil showed that $4 \mathrm{~h}$ EVLP on extended-criteria donor lungs could recover the mean $\mathrm{PaO}_{2}$ and oxygenation capacity, and static compliance improved especially in the first $2 \mathrm{~h}$ but failed in next $2 \mathrm{~h}$. No change in pulmonary vascular resistance was observed. Thus these lungs were precluded transplantation due to complex physical conditions [27].

\section{Effect of EVLP on Marginal Lungs and more Complicated Cases}

Some more complicated cases, such as donors as brain-dead patients implanted with mechanical circulatory support system or bilateral lungs procured and transplanted after using of portable normothermic perfusion device, reaching the aim of reducing ischemic injury while assessing the marginal donor lungs for suitability [28]. 


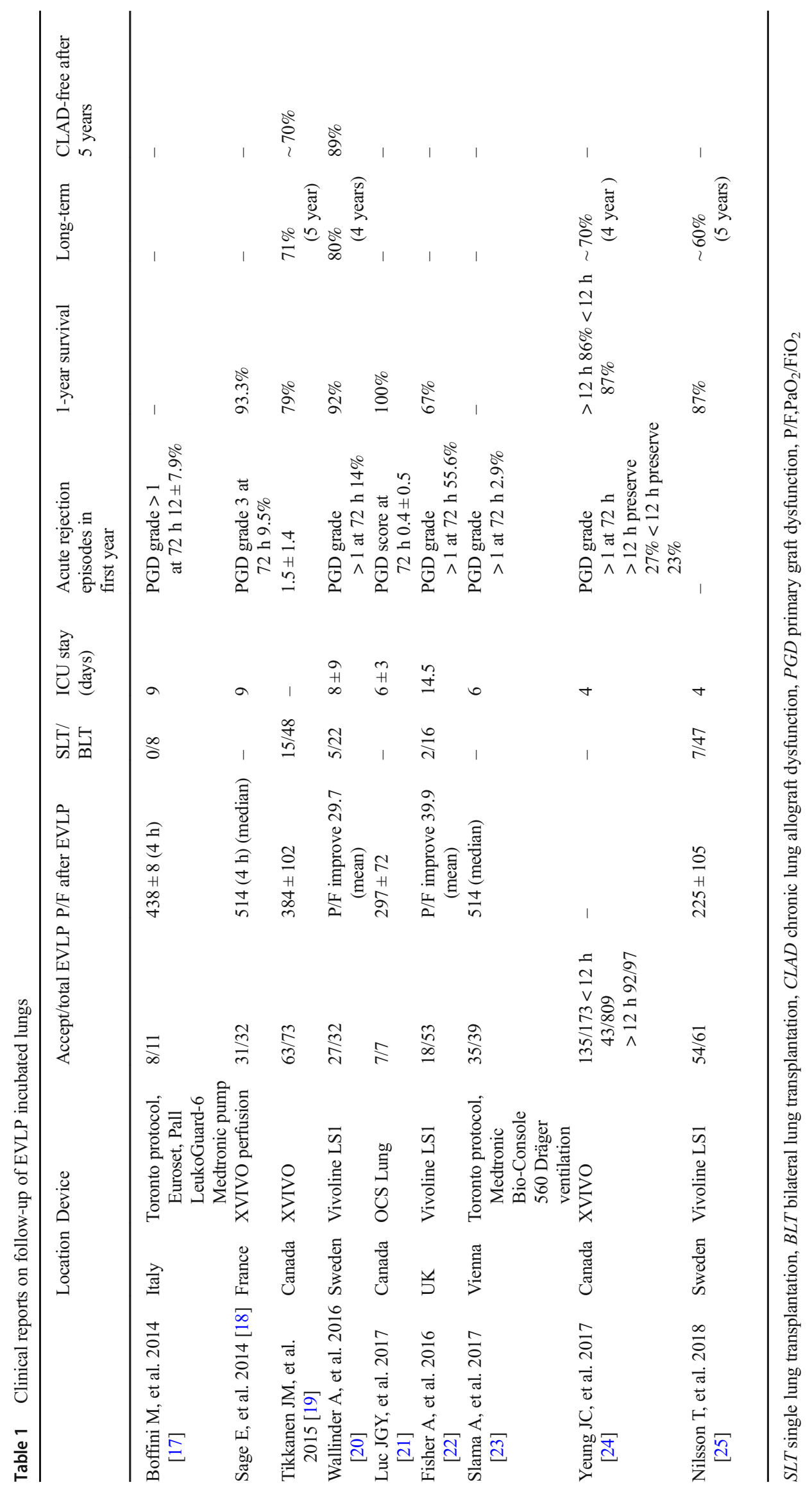


A large and non-randomized trial DEVELOP-UK, showed that $34 \%$ untransplantable lung could be put into procedure after EVLP. Survival at 12 months was 0.67 comparing to 0.80 after EVLP [22]. Not only the comparison was done on ventilation period, stay intensive care, PGD3, ECMO application, hospital stay, chest infection, lung function, or rejection by 12 months, but also, further cost predictors including life quality on joining the waiting list, type of transplant and number of lungs transplanted were stated. EVLP transplant cost is approximately $£ 35,000$ more and is likely to be acceptable by means of increasing the number of transplantable donor lungs and reduce waiting.

Toronto, Swedish, and UK experience, followed by Paris, Madrid, Vienna, Milan, etc., together showed a good early survival for EVLP lungs, including from unusable to usable donor organs. For a center like Toronto, large volume of DCD donors reserved EVLP as an assessment tool rather than a reconditioning. EVLP is becoming a technique not only to expand the limited donor pool, but more important, to provide more hope by prolonging the perfusion times with better recondition based on Toronto's experience.

Thus, an impetus to conduct a prospective randomized clinical trial compared patients who underwent transplantation with or without EVLP, including 193 lung Tx were initiated at the Medical University of Vienna. Total cold ischemic time was significantly longer in EVLP group and with lower incidence of primary graft dysfunction $>1$ at all time. Thus, EVLP is believed to indicate excluding lungs with functional impairment, while extending total preservation time for usable ones [23].

People also wondered if EVLP could help ameliorate a seemingly worse early outcome exhibited by the data collected in a short period after surgery. In a review of EVLP used in two Scandinavian centers, arterial oxygen tension/inspired oxygen fraction ratio at arrival in ICU, median time to extubation, median ICU length of stay were significantly worse and longer in EVLP groups. No difference in FEV1.0\% at 1 year, 1-year survival rate, and 5-year survival between EVLP group and non-EVLP group. Although comparable results could be reached, it, in other words indicated that EVLP could ameliorate a worse early outcome immediately after transplantation, possibly due to the poor condition of organs or the receivers [25]. Experience from French researchers showed that after recovery procedure of EVLP, initially rejected lungs were used to perform double lung transplant with similar rate of PGD, survival and 30-day mortality comparing to conventional donors [18]. No definitive conclusion of EVLP could be reached based on the limited data from human, due to different levels of donor lung condition, preservation methods, and inconsistent data collection.

However, a higher conversion rate (total number of lungs transplanted to the total number of lungs placed on EVLP) requires abundant experience of manipulating acceptable lungs in the center, which is not quite conservative on the standard application. Further, some preliminary results also showed that time of ventilation and ICU stay might be longer than conventional transplantation without EVLP, this could be attributed to the less optimal organ selection and incubation time varied of EVLP in different centers. By splitting one long cold ischemic time into two shorter ones, for more than $12 \mathrm{~h}$ of preservation time, Toronto EVLP technique was used to compare mean lung preservation time, median hospital and ICU length of stay, PGD grade and survival rate with any significance. Increasing recipient age was showed to be a significant variable affecting survival [24]. Immediate graft function or lungs on long preservation time $(>12 \mathrm{~h}$ ) in recipients were not the cause of death, but the early lung injury showed an association with death cause of infection or chronic rejection. Optimizing the time and condition of incubation, finding a precise condition for a specific group will hold the future promise.

\section{Experimental Intervention on Donor Lungs Based on the EVLP Platform}

In the recent 10 years, EVLP has been proved to be valuable as a reassessment tool to increase donor utilization [29]. EVLP began to be applied in combination with regenerative medicine advancement, such as stem cell biology in these 23 years [30]. Animal models of EVLP have been developed and helped to explore more novel experimental platforms that can be used to do translational research on pulmonary physiology and transplant medicine [31].

\section{To Find Optimized Markers of Quality Determination}

Assessment and optimization of donor lungs are recognized to be necessary for reducing both early and late posttransplantation morbidity and mortality, as well as reduce overall costs and resource utility. In vivo prior to organ procurement and EVLP circuits synergistically enhance the donor lung quality. EVLP may facilitate assessment and/or reconditioning of borderline lungs, with a conversion rate of $46 \%$ and good short-term survival with $100 \%$ survival at 3 months [32].

Extracellular microvesicles (EVs) have been testified for diagnostic potential to study the kinetics and tissuerelated profiles of pulmonary EVs with EVLP. Monocytes (CD14), endothelium (platelet endothelial cell adhesion molecule 1), and pulmonary parenchyma (epithelial cell adhesion molecule) have been shown to contribute to perfusate exchange with Steen Solution. EV protein cargoes also showed differences, providing insights to pulmonary pathologic processes [33]. Particle flow in exhaled air 
helped online assessment of the impact of ventilation before tissue change presentation [34].

Another research pathway is to focus on lung function parameters. The pressure of arterial oxygen to the fraction of inspired oxygen concentration $\left(\mathrm{PaO}_{2} / \mathrm{FiO}_{2}, \mathrm{P} / \mathrm{F}\right)$ ratio has been recognized as a gold standard for assessing the transplantable lungs. Fluctuation of $\mathrm{P} / \mathrm{F}$ ratio at different $\mathrm{FiO}_{2}$ might affect decision-making [35]. A comparing of swine and human rejected lungs was performed after $2 \mathrm{~h}$ EVLP, partial pressure of oxygen/fraction of inspired oxygen (PF) ratio was related to airway and parameters, static compliance and vascular resistance in both groups. Thus, difference in all the parameters would further have the value of judgment for suitability for transplantation [36].

Further, dynamic change of functional data related to inflammation status of lung, thus affected the short-and long-term prognosis of the transplantation. Porcine lung samples were collected and subdivided into in vivo cold static preservation group and EVLP group. Acute lung injury-related gene expression was measured and peaking time with continual period analyzed. Six hours would be the utmost change in gene-level, which affects $\mathrm{P} / \mathrm{F}$ ratio and interstitial inflammation [37]. Lungs recovered from uDCDDs were assessed by $4 \mathrm{~h}$ EVLP and CT scan. Lungs receiving EVLP included immediate edema (pulmonary embolism, long ischemic time, and ruptured aneurysm) and myocarditis. Logistical challenges concerning the consent procedure and donor medical profile might contribute to the hindering of lung acceptance [38]. Special case was reported that a donor with medical history of hemolytic anemia and known cold agglutinin, whose lungs had a total cold ischemia time of $6.5 \mathrm{~h}$. Established clots and aggregates could be observed from the initiation of EVLP, leading to florid pulmonary edema and cessation of EVLP. Impact of hypothermic preservation on cold agglutinin donors should be consulted before assessment [39].

\section{To Manage Unacceptable Lungs with Initial Refusal Due to Critical Conditions}

Some experimental trials have been ongoing to find potential repair methods, which will change the initial assessment determination. Lungs from brain-dead donors rejected for transplantation were stored $10 \mathrm{~h} 4{ }^{\circ} \mathrm{C}$ and performed $1 \mathrm{~h}$ normothermic EVLP with Steen Solution. EVLP improved oxygenation capacity and protected the lung tissue structure [40]. Longer cold ischemic period of $10 \mathrm{~h}$ low-potassium dextran flush (Perfadex) at $4{ }^{\circ} \mathrm{C}$ and $6 \mathrm{~h}$ EVLP with short cold ischemic time $(2 \mathrm{~h})$ or long time $(10 \mathrm{~h})$ preservation of lungs did not affect lung function after transplantation [40, 41]. Thus, a combination of cold and warm preservation techniques could have the promise to improve lung transplantation logistics and outcomes (Table 2).

\section{Thrombosis}

Donor lung thrombosis is a big challenge for transplantation result. Donor lungs from DCD Swedish pigs were perfused with Perfadex ${ }^{\circledR}$ solution with alteplase. Better blood gas results and slightly lower PVR could be reached in antithrombotic treatment group [43]. A report of case showed pre-treatment-donated lung with acute pulmonary embolism by a fibrinolytic agent, urokinase, during EVLP, which made a successful transplant [55]. Thermography could help to detect a mal-perfused region by surface temperature during EVLP [56]. Donor lung thrombus is also recognized as cause of PGD. Plasmin treatment during EVLP could see fewer signs of histologic injury with lower caspase- 3 and -7 activity, thus reducing the IR injury [42].

\section{Ventilator-Induced Lung Injury}

Ventilator-induced lung injury (VILI) could also happen in EVLP with fixed ventilator settings and under the monitoring of compliance, which is indicated by airway pressure-time curve (stress index). An increase in cytokine concentrations after $4 \mathrm{~h}$ EVLP in the non-protected lungs with longer durations of mechanical ventilation, ICU, and hospital lengths of stay could be seen, which are significantly correlated by stress index [44]. Normothermic cellular EVLP has been put into research scenario. Agonal hypoxia and $1-2 \mathrm{~h}$ warm ischemia with or without ventilation lungs could reach normalized hemodynamics and compliance after 24-h EVLP. Only DCD lungs showed impaired oxygen [45]. Early donor postmortem ventilation and timely procurement lead to better graft function.

\section{Ischemia-Reperfusion Injury}

Due to the multiple steps of organ procurement procedure, ischemia and reperfusion periods are varied in different settings and have major effect on the donor lung function. Various monitor methods and intervention approaches have been investigated, which are still demanding more clinical evidence to confirm.

To reflect the increase of ischemia reperfusion mechanism, endogenous production of exhaled carbon monoxide $(\mathrm{eCO})$ is used in the selection of lung grafts. A porcine model and laser $\mathrm{eCO}$ spectrometer measurement gave primary result that 24-h cold ischemia would have higher systematical eCO [46]. Apart from physiologic variables such as pulmonary mechanics, gas exchange, and pulmonary vascular resistance during the practice of reassessing and reconditioning of marginal lungs, real-time computed tomographic (CT) imaging has also 


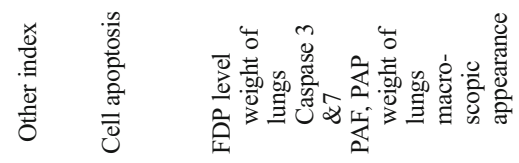

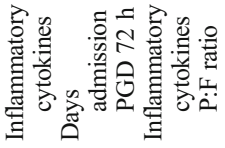

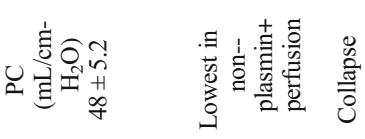

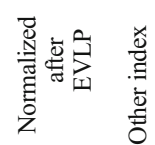

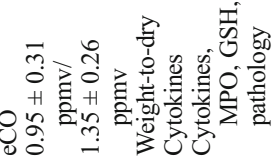

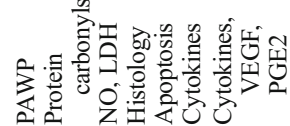

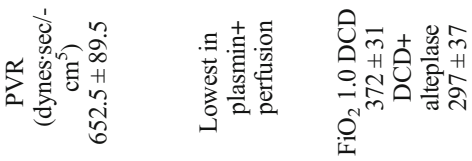

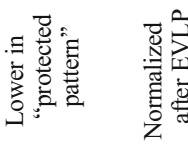

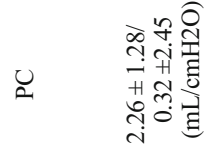

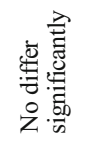

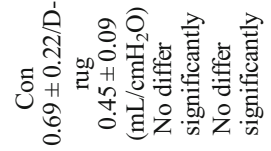

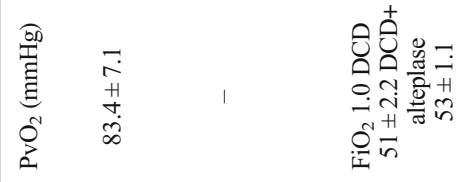

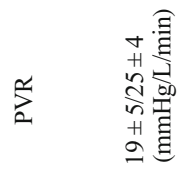

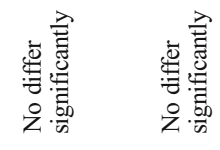

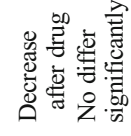

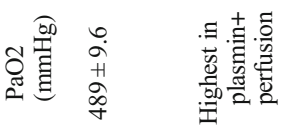

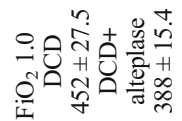

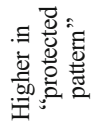

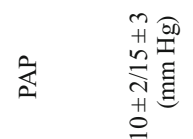

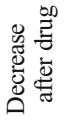

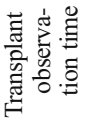

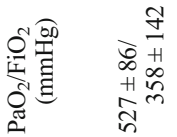

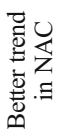

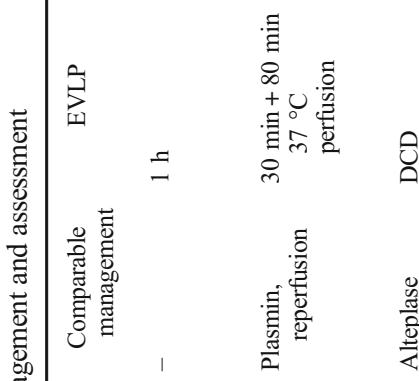

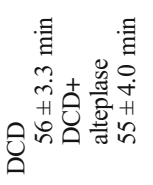

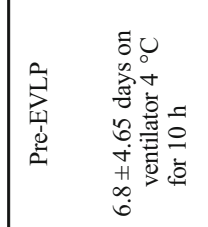

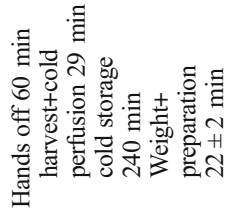

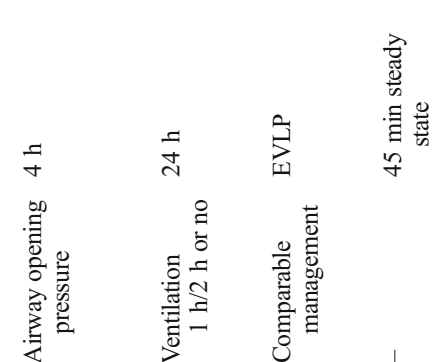
त)

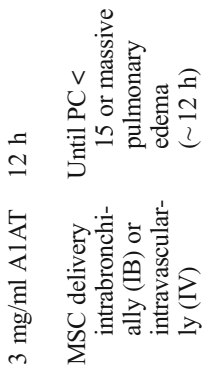

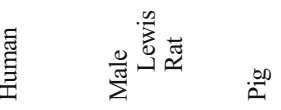

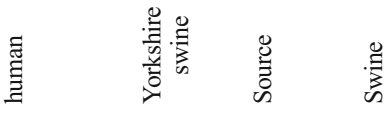
证

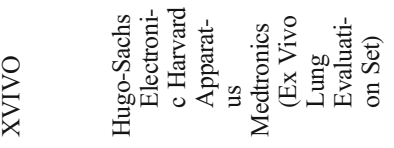

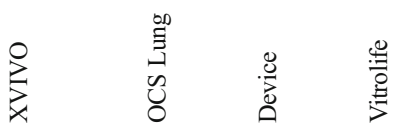

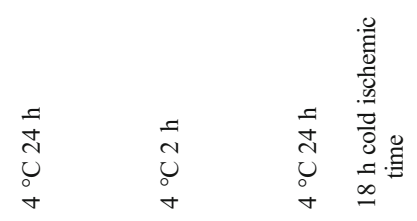

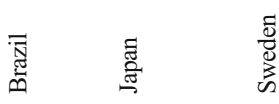
至 芯

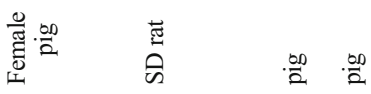
离

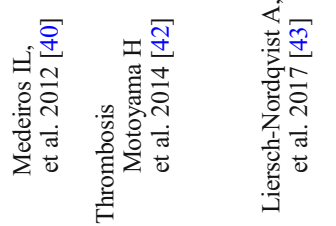

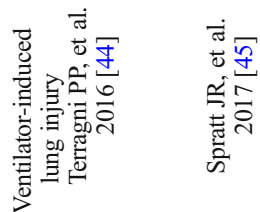

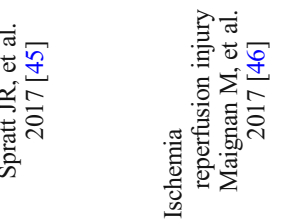

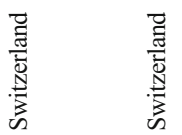
䒿 䔍

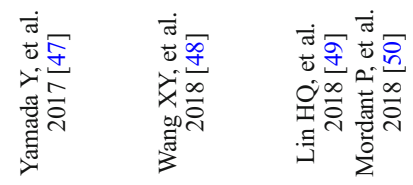


been reported to be used [57]. MRI was reported to have the capability of assessing the organ function in ischemic injury. Higher wet/dry ratios and IL-8 tissue levels with prolonged oxygen washout could be seen in ischemic lungs. Oxygenenhanced imaging showed promise in detection of affected lung segments in advance [58].

Volatile anesthetics have been shown to have protection effect against reperfusion injury in series of experimental settings [48]. Reduced LDH, protein carbonyl, 3-nitrotyrosine, cytokine-induced neutrophil chemoattractant factor, 1 and $\mathrm{TNF}-\alpha$ could been seen in drug treatment group. Lungs also had less perivascular edema and improved static pulmonary compliance and peak airway pressure. Argon (Ar) is also known as organ-protective gas, but no beneficial effects of a high concentration of Ar on cold pulmonary ischemiareperfusion injury had been detected [59].

Several anti-oxidants or inflammation-related pathway regulators are selected to act as therapeutic methods with EVLP, providing preliminary results. A1-Anti-trypsin (A1AT) is used to treat emphysema in A1AT-deficient disease, which has been shown that it also had anti-inflammatory properties to attenuate ischemia-reperfusion injury. Pig lungs with treatment showed reduced pulmonary arterial pressure, pulmonary vascular resistance, and airway pressure; improving both dynamic and static pulmonary compliance, reducing pulmonary edema (wet-to-dry ratio), pulmonary cell apoptosis and proinflammatory cytokine levels (interleukin- $1 \alpha$ and -8 ) in the perfusate [49]. Inhaling of $N$-acetylcysteine could also be used to treat ischemia-reperfusion injury by inhibited inflammation-related myeloperoxidase activity during EVLP and nuclear factor- $\mathrm{kB}$ activation at the end of reperfusion could be observed [47].

Trimetazidine (TMZ) has been used clinically in ameliorating ischemia reperfusion injury, which has also been shown to improve immediate post-transplant lung function. Better oxygenation and gas exchange as well as lower tissue thiobarbituric acid levels, myeloperoxidase activity, and protein concentrations could be reached [60]. Ascorbic acid adding to perfusate, prolonged lung viability by $80 \%$, and increased the hyperpolarized ${ }^{13} \mathrm{C}$ bicarbonate signal [61], which was to increase the lung's energy charge, slowing the decline of the perfused lung's mitochondrial activity ex vivo. More commonly used in clinic, $\beta 2$-adrenoreceptor agonist inhalation ameliorated the lung function and compliance, enhancing cAMP and total adenosine nucleotide (TAN) levels with more cystic fibrosis transmembrane conductance regulator (CFTR) gene expression [62].

Human mesenchymal stromal cells (MSCs) and MSCderived extracellular vesicles (EVs) have been used long term for immunomodulation and repair of ischemia reperfusion injury. MSC-/EV-treated lung had attenuation of dysfunction status and injury (decreased edema, neutrophil infiltration, and myeloperoxidase levels). Proinflammatory cytokines 
(IL-17, TNF- $\alpha$, CXCL1, and HMGB1) were decreased and upregulation of keratinocyte growth factor, prostaglandin E2, and IL-10 could be seen. Downregulated iNKT cell-produced IL-17, macrophage-produced HMGB1, and TNF- $\alpha$ after hypoxia/reoxygenation as well as transendothelial migration might contribute the recondition mechanism [63]. In the protocol of $18 \mathrm{~h}$ cold preservation and $12 \mathrm{~h}$ normothermical EVLP, mesenchymal stromal cells (MSCs) were administered endobronchially or via pulmonary artery. It was only through intravascular administration that MSCs could be retained in lung parenchyma. Expression of vascular endothelial growth factor (VEGF) was increased and IL-8 was decreased [50].

\section{Pulmonary Vascular Remodeling}

Pulmonary vascular resistance is one of the most important function parameters to be monitored during and post-surgery. Better graft oxygenation, dynamic pulmonary compliance, and reduced pulmonary vascular resistance were observed in the bronchodilator-treated group after $4 \mathrm{~h}$ transplantation, with higher adenosine 5'-triphosphate and cyclic adenosine monophosphate levels [52]. Using $24 \mathrm{~h}$ of cold ischemia as defined organ stress and $12 \mathrm{~h}$ EVLP on the basis of an acellular or a cellular perfusate composition, results showed that there were no significant difference on aerodynamic parameters but higher pulmonary artery pressure and vascular resistance in the cellular group [51], which showed an unignorable consideration of perfusate composition on pulmonary vascular physiology. Accordingly, different precondition of lungs before EVLP, incubation time, as well as model species all contributed to various pulmonary physiologies. Pulmonary artery pressure, pulmonary vascular resistance, and compliance are fundamental factors to be analyzed in vascular remodeling research. However, more common histology or biomarkers are needed to be explored as supplementary to set-up difference.

\section{Gastric Acid Aspiration}

Adding surfactant before EVLP improved the function of donor lungs injured by gastric juice aspiration [53]. Donor lungs with gastric aspiration injury model were constructed and after retrieval, if exogenous surfactant administrated, IL-1 $\beta$, IL-6, IL-8 and secretory phospholipase A2 levels were reduced, minimum surface tension was recovered to normal, and lung function was better in post-transplant monitor [54].

\section{To Predict Graft Function and Complications Post-Surgery}

Time and function are the two main factors which are believed to have serious effect on the long-term potential of the transplantable lung (Table 3).

\section{Prediction of Respiratory Mechanics}

Exceeding $12 \mathrm{~h}$ EVLP has not been taken into clinical practice previously. EVLP management could get another $44 \%$ rejected lungs to be transplantable with lower expression of vascular injury markers. Perfusate IL- $1 \beta$ concentrations contributed to a model for predicting final EVLP outcome after $2 \mathrm{~h}$ with inverse correlation to $24 \mathrm{~h}$ post-transplant recipient oxygenation [64].

Organ Care System (OCS) using STEEN's solution enriched with erythrocytes has been shown the most favorable PAWP and PVR, which were considered as early and late predictors of transplant outcome [65]. After 10-h EVLP with autologous blood and STEEN solution, assessed lungs showed robust increase in PVR ( $\triangle \mathrm{PVR}$ ) up to $4 \mathrm{~h}$ of perfusion. Decreased HPV (hypoxic pulmonary vasoconstriction) response inversely correlated to cytokine concentrations of Interleukin- 6 and tumor necrosis factor- $\alpha$, which indicated that there was a subclinical deterioration of lung function [66].

\section{Prediction of PGD Occurrence}

Prediction of possibility of primary graft dysfunction (PGD) will provide great help during the assessment procedure. Metabolomics of EVLP perfusate helped further to testify the function of donor lungs, which was associated with early transplantation outcomes. Palmitoyl-sphingomyelin, 5aminovalerate, and decanoylcarnitine were related to 1-h EVLP group on PGD3; while N2-methylguanosine, 5aminovalerate, oleamide, and decanoylcarnitine were among the 4-h EVLP group on PGD3. These could be considered as potential biomarkers to improve selection of marginal lungs on EVLP, however the specificity needs to be further explored [67].

To find some biomarkers for the purpose of prediction might help for pre-transplantation evaluation. M30 (indicating epithelial apoptosis) was much higher in the PGD Group at 1h EVLP and 4-h EVLP perfusate. High mobility group box 1 (HMGB-1, related to cell death and inflammation) from 1-h to 4-h EVLP was significantly greater in the PGD Group. Both markers showed higher mortality correlation [68]. According to Hashimoto's report [69], 11/100 EVLP lungs developed PGD grade 3 within 72 h post-surgery. Levels of sICAM-1 (soluble intercellular adhesion molecule 1) at $1 \mathrm{~h}$ and sVCAM-1 at 1 and $4 \mathrm{~h}$ were significantly higher in the PGD group compared with the non-PGD group, correlating with endothelial activation. Thus, adhesion molecules may help identify donor lungs at higher risk of PGD during EVLP.

It was stated that perfusate protein expression during EVLP could differentiate lungs with good outcome from lungs PGD3 after transplantation. High expression of stem cell growth factor- $\beta$ expression for $1 \mathrm{~h}$ helped exclude nonacceptable lungs, while $4 \mathrm{~h}$ IL-8 and growth-regulated 


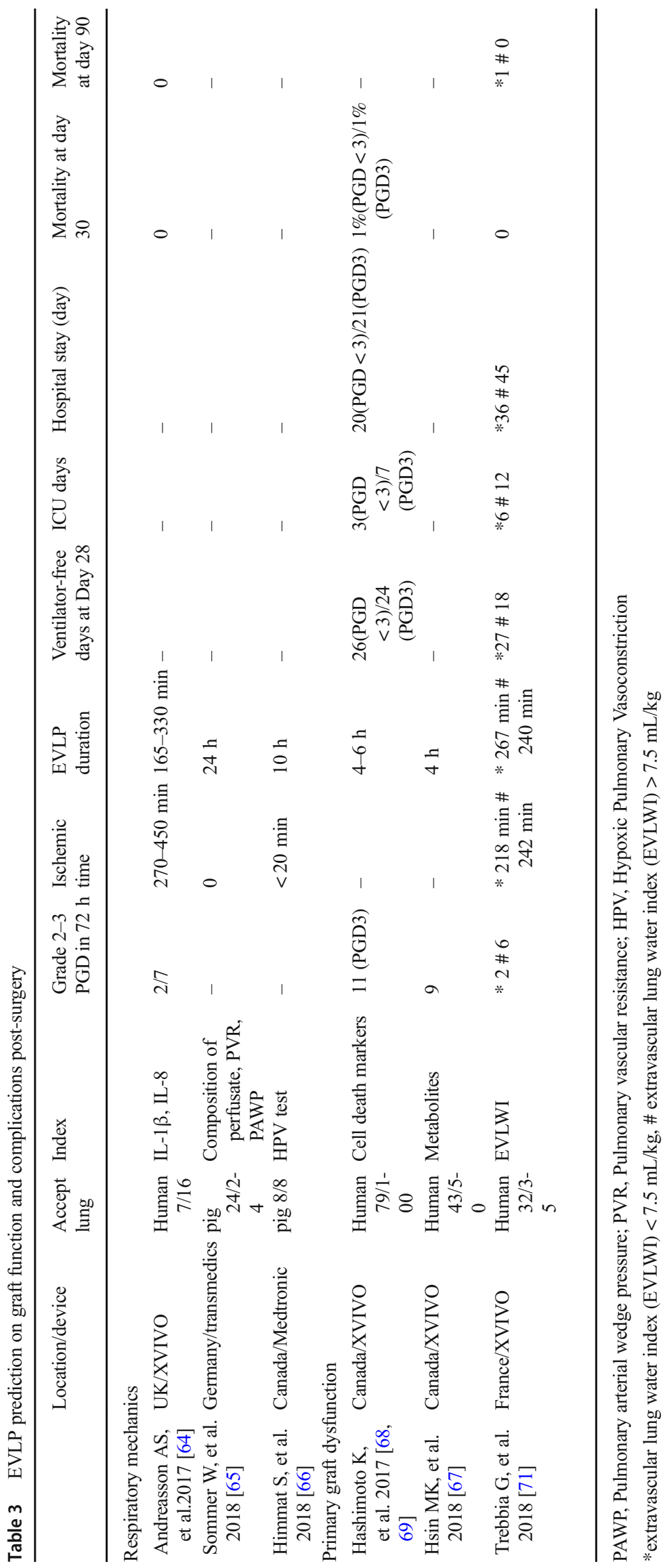



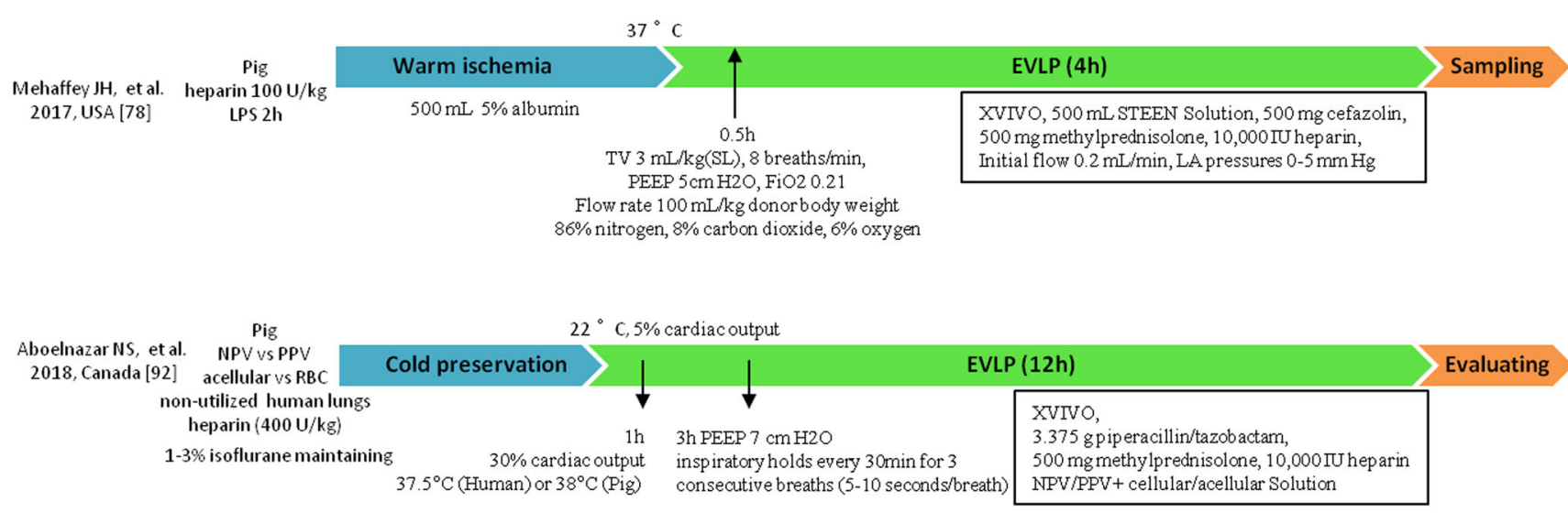

\begin{tabular}{|c|c|c|c|c|c|}
\hline \multirow{3}{*}{$\begin{array}{l}\text { Zinne N, et al. } \\
\text { 2018, Germany [77] }\end{array}$} & \multirow{3}{*}{$\begin{array}{c}\text { Pig } \\
\text { Infection model } \\
\pm \text { antibiotics }\end{array}$} & Warm ischemia & $\operatorname{EVLP}(2 \mathrm{~h})$ & $\downarrow$ & Flushing and re-transplant \\
\hline & & \multirow{2}{*}{$\begin{array}{c}1 \text { L Perfadex } \\
0.3 \text { ml THAM } \\
2 \pm 3 \% \text { isoflurane maintaining }\end{array}$} & Ventilation & Ventilation Ceased & \multirow{2}{*}{$\begin{array}{l}\text { 1LPerfadex } \\
0.3 \mathrm{ml} \text { THAM }\end{array}$} \\
\hline & & & $\begin{array}{l}\text { Organ Care System }{ }^{m}, 2 \mathrm{~L} \text { albumin- } \\
1000 \mathrm{ml} \text { porcine blood, } 500 \\
1 \text { unit multivitamins, } 1 \text { g glucose, } 1\end{array}$ & $\begin{array}{l}\text { taining STEEN Solution }{ }^{\text {tw }} \text {, } \\
\text { nethylprednisolone, } \\
\text { moxicillin, } 800 \text { mg colistin }\end{array}$ & \\
\hline
\end{tabular}

Fig. 1 EVLP set-up on novel strategies on lung repair and rehabilitation

oncogene- $\alpha$ expression marked PGD3 high incidence [70]. Lung edema measurement could also contribute to PGD happening. Single transpulmonary thermodilution with extravascular lung water index (EVLWI) is discovered to be a new tool to assess lung graft edema during EVLP. Donor lungs with EVLWI $>7.5 \mathrm{ml} / \mathrm{kg}$ were likely associated with a higher incidence of Grade 2 or 3 PGD at Day 3 [71]. Data from animal models and human beings have shown some difference, whether due to experimental set-up or observational index. Biomarkers or extreme conditions in animal models and longer follow-up in human trails should be complementary to demonstrate the value of ELVP further.

\section{To Deliver Novel Strategies on Lung Repair and Rehabilitation Before Transplantation}

Preclinical studies have also shown a great potential of EVLP as a platform of delivery of novel therapies to repair organs or even initiate rehabilitation before the surgery [72]. Several therapeutic approaches began to initiate administering drugs, such as antibiotics, fibrinolytics, and vasodilators, aiming to avoid systemic toxicity. Nowadays, animal models are used to break through the contraindication barrier for lung transplantation unprecedentedly.

\section{Anti-Inflammatory Strategy}

Assess emerging therapeutics on organ function in ARDS is an unmet need in drug research for ARDS. EVLP has shown promise as a unique human platform for preclinical study of chemical small molecules [73] as well as anti-inflammatory effect of aspirin in ARDS treatment [74]. In terms of expanding the organ pool for transplantation, neutrophil adhesion markers were shown to be reduced by $12 \mathrm{~h}$ EVLP with high-dose antibiotics (ciprofloxacin $400 \mathrm{mg}$ or azithromycin $500 \mathrm{mg}$, vancomycin $15 \mathrm{mg} / \mathrm{kg}$, and meropenem $2 \mathrm{~g}$ ) [75, 76]. High-dose antibiotic therapy in EVLP followed by autotransplantation has been reported to be a new method to treat multidrug-resistant lung infections. Overall mortality rate could be cut off by 50\% comparing to the control group [77]. For a septic lung, $4 \mathrm{~h}$ EVLP has shown improvements in oxygenation and dynamic compliance of donor lung [78]. Prolonged EVLP incubation, different systems with different antibiotics, and time or temperature controlled ventilation have shown promising results (Fig. 1).

Drugs directly targeted to inflammation pathways in EVLP were also explored, such as AdhIL-10 gene therapy [79, 80], NF-KB inhibitor pyrrolidine dithiocarbamate (PDTC) [81], methylprednisolone [82], and neutrophil elastase inhibitors [83]. EVLP could further make donor lung less immunogenic, however, most experimental design put the management as a precondition, which should be further discussed in ethical context.

Nowadays, a leukocyte filter (LF) is routinely incorporated into the EVLP circuit [84]. Removed passenger leukocytes could reduce pyroptotic reactions [85] and pro-inflammatory cytokines [86]. Another way to modify EVLP in order to reach a better post-transplant functional outcome is to optimize the level of perfusate oxygenation, such as $40 \% \mathrm{O}_{2}$ [87] or ventilated with $2 \%$ hydrogen [88, 89], through 
a

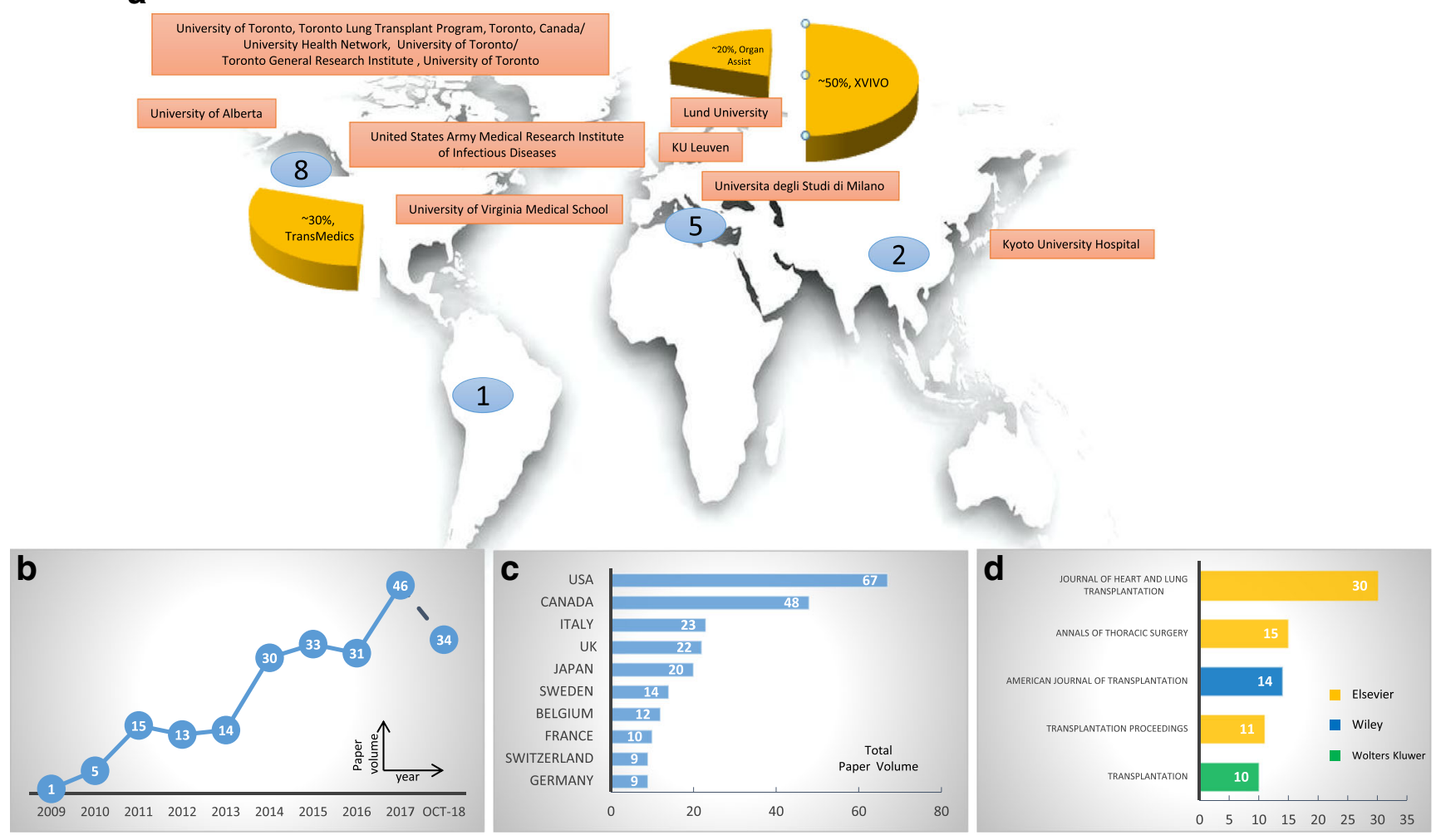

Fig. 2 Statistics from the perspective of the publisher. Numbers of centers are involved in performing clinical researches (a) and publications are continuously increasing every year (b) from top centers distributed all

upregulation of heme oxygenase-1 and promoting mitochondrial biogenesis [90] and innate mechanisms of repair [91]. NPV could also reduce lung edema and lower composite acute lung injury [92].

Recovery of lungs followed the stages of cellular death, cellular preservation, reorganization, and invasion. Steen solution was believed to possess antioxidant properties via downregulation of NADPH oxidase activity and enhanced production of NO [93], exerting antioxidant effects on parenchymal cells [94]. Releasing of medium-high molecular weight hyaluronan and transcription of hyaluronan synthases were also induced by EVLP [95]. ATL802, an adenosine A2B receptor antagonist could augment reconditioning of EVLP with significantly improved lung function and attenuated pro-inflammatory cytokine production, such as IL-12, neutrophil infiltration, vascular permeability, and edema [96, 97].

Microbial Niche in airway and lung is an arising focus for lung immunology in transplantation research, which would have a direct relationship with infection, one of the most intractable problems post-surgery. EVLP provides an isolated platform to study interaction of lung tissue and microbiota. Initial report showed that EVLP could decrease bacterial loads and receivers were survived to hospital discharge [98]. It was confirmed that microbiota signal in airway could remodel the transplanted lung immune characteristics [99, 100] and also over the world (c) with clinical trials (number in a). Further, top journals have taken over most papers on EVLP (d)

play a role in development of bronchiolitis obliterans syndrome (BOS) [101]. Dynamic observation of lung microbiome transfer and alteration will be an upgrade of study interest [102, 103] and EVLP might become an intermittent bridging environment, providing a timely control of dysbiosis and subsequent persistent infection, as well as rejection, by manipulating microbiome directly. Further assumption inspired by xenogeneic transplantation study, is that genome editing tool CRISPR-Cas9, will not only help to induce immune tolerance [104], but also to engineer some genetic modifications, such as resistance to infection by way of EVLPbased research.

\section{Anti-Rejection Treatment}

Passenger leukocyte transfer could result in acute rejection with mechanism of alloantigen expression on donor cells. Three hours of EVLP could reduce donor leukocyte transfer into the recipient and migration to lymph nodes, as well as diminished recipient T cell infiltration [105]. EVLP could further reduce inflammatory reaction related to a following PGD occurrence [106], although some extracorporeal life support is being used early in patients who have PGD [107]. Inhaled noble gases such as argon and xenon, based on their organ protective effects have been recognized to have effect of 
reducing primary graft dysfunction incidence [108]. This is also a promising area to be explored, as lung rehabilitation would be initiated in EVLP pre-transplantation, aiming to reduce the rejection or graft failure rate.

\section{Anti-Ventilation Injury Management}

When procuring lungs from an uncontrolled donor after circulatory determination of death following an extended period of warm ischemia, EVLP with continuous positive airway pressure, and protective mechanical ventilation could get a satisfactory result after 6 months of surgery [109]. Pressuredirected airway pressure release ventilation strategy showed to have more benefit for rehabilitation of severe injury [110].

\section{Anti-pulmonary Edema Performance}

An open left atrium (LA) (pressure of $0 \mathrm{mmHg}$ ) or closed LA (pressure of $5 \mathrm{mmHg}$ ) was used in EVLP settings. Several open atrium cases got severe pulmonary edema in $7 \mathrm{~h}$ EVLP; however, the closed atrial technique leads to significantly less edema and superior lung physiology [111]. But in another report, an acellular perfusate and a closed left atrium resulted to a more pronounced lung edema and lower lung compliance [112], confirming a previous thought that alternative perfusion solution might contribute to lung edema formation [113].

\section{Modulation and Merchandising of EVLP Platform Leading to Organ "Ready-to-Use" Era}

\section{Modulation of Existing EVLP Procedure and Application Model}

Basic devices of all the commercialized EVLP platforms commonly include a ventilator, an endotracheal tube, a lung chamber, a blood reservoir, pump, heater, membrane lung, leukocyte filter, and cannula. Steen ${ }^{\mathrm{TM}}$ solution is the mostly used perfusate with modifying of the solutes nowadays. For the transportable EVLP device OCS ${ }^{\mathrm{TM}}$, cold storage was significantly shortened with all the way of physiological temperature during transportation. Mainstream techniques in application nowadays include the Toronto technique, the Lund technique, and Hannover-Madrid technique. Modification of EVLP procedure are from the aspects of flow control [114], various perfusion time [115], cooling or hypothermic preservation [116], as well as alter the work flow of the transplantation, staged model to do liver-after-lung transplantation [117] and split lung transplantation in two centers with a distance of $2250 \mathrm{~km}$ by running EVLP [118]. The technique of EVLP- based lung split, preservation and transportation adopted in smaller children, is currently under discussion [119].

\section{Merchandizing of the EVLP as a Practical System}

There are up-to-date commercialized devices for clinical EVLP use including: Organ Care System ${ }^{\mathrm{TM}}$ Lung (OCS, Transmedics, MA); Lung Assist ${ }^{\circledR}$ (Organ Assist, Netherland); Vivoline ${ }^{\circledR}$ LS1 (acquisition by XVIVO) + XPS $^{\mathrm{TM}}$ (XVIVO Perfusion AB, Sweden); and Toronto EVLP system (XOR Labs Toronto, Canada-invested by Xenios AG, Germany). The two most clinically relevant and commercially available devices currently in clinical trials are XVIVO Perfusion System (XPS Perfusion, Goteborg, Sweden) and Organ Care System (Transmedics, Andover, MA). Our review focuses on the needs met by ex vivo lung perfusion, and the clinical literature on both devices [120]. Semiautomated systems with disposable kits, such as XVIVO Perfusion System, aims at making EVLP procedure more standardized. Numbers of centers are involved in performing clinical researches (Fig. 2a) and publications are continuously increasing every year (Fig. 2b) from top centers distributed all over the world with clinical trials (number in Fig. 2a). Further, top journals affiliated to famous publishers have taken over most papers on EVLP (Fig. 2c).

It is believed that machine perfusion of pulmonary allograft is mandatory in uncontrolled DCD lung transplantation [121]. Preservation, resuscitation, assessment, repair, and conditioning are essential points that EVLP provided thus making lung transplantation plannable. Portable normothermic EVLP has been evaluated in clinical trials using standard and extended-criteria donor lungs [122, 123]. Reconditioning with the OCS ${ }^{\text {TM }}$ Lung could improve $\mathrm{PaO}_{2} / \mathrm{FiO}_{2}$ ratio, reaching a comparable 1-year survival rate and living conditions [124]. Using 24-h EVLP with autologous whole donor blood circulating on OCS, only whole blood and red blood cell incubation lungs could meet clinical standards for transplantation at $8 \mathrm{~h}$; acellular perfusion with Steen solution was limited to $6 \mathrm{~h}$ due to high vascular resistance, edema, and worsening compliance [125]. Some large scale of prospective, randomized multicenter trials are onsite recruiting (Table 4), focusing on expandability application of EVLP, will demonstrate the precise analysis of EVLP on organ transporting, and expanding pursuit.

\section{Portable EVLP Nurturing the Cost-effective Organ Transportation}

Initial experience of EVLP showed that it could be an effective method to increase suitable lung [126] and allowing distant organ allocation [127], but more cost-effective alternatives need advisable effort to seek for. A debate issue arising, concerning both medical and economical aspects, is whether 
Table 4 EVLP clinical trials (data collected from ClinicalTrials and CHICTR)

\begin{tabular}{|c|c|c|c|}
\hline On board trail title & Sponsor & $\begin{array}{l}\text { Initial } \\
\text { recruitment }\end{array}$ & Device \\
\hline $\begin{array}{l}\text { Increasing Lung Transplant Availability Using Normothermic Ex Vivo } \\
\text { Lung Perfusion (EVLP) at a Dedicated EVLP Facility } \\
\text { (ClinicalTrials) }\end{array}$ & Lung Bioengineering Inc. & 2018 & $\begin{array}{l}\text { Centralized Lung } \\
\text { Evaluation System }\end{array}$ \\
\hline $\begin{array}{l}\text { Application and promotion of normothermic ex-vivo lung perfusion for } \\
\text { extended criteria lungs in lung transplantation (ChiCTR) }\end{array}$ & $\begin{array}{l}\text { Shanghai Pulmonary Hospital, } \\
\text { China }\end{array}$ & 2018 & $\begin{array}{l}\text { XVIVO Perfusion System } \\
\text { (XPS) with STEEN so- } \\
\text { lution }\end{array}$ \\
\hline $\begin{array}{l}\text { Ex Vivo Lung Perfusion in Bergamo Lung Transplant } \\
\text { Program(ClinicalTrials) }\end{array}$ & $\begin{array}{l}\text { Papa Giovanni XXIII Hospital, } \\
\text { Italy }\end{array}$ & 2017 & Not specified \\
\hline $\begin{array}{l}\text { The University of Alberta Negative Pressure Ventilation Ex-Vivo Lung } \\
\text { Perfusion (ClinicalTrials) }\end{array}$ & University of Alberta & 2017 & NPV-EVLP \\
\hline $\begin{array}{l}\text { Trial to Evaluate the Safety and Effectiveness of the Portable Organ } \\
\text { Care System }\left(\mathrm{OCS}^{\mathrm{TM}}\right) \text { Lung System for Recruiting, Preserving and } \\
\text { Assessing Non-Ideal Donor Lungs for Transplantation } \\
\text { (ClinicalTrials) }\end{array}$ & $\begin{array}{l}\text { TransMedics (including centers in } \\
\text { USA) }\end{array}$ & 2017 & OCS lung preservation \\
\hline $\begin{array}{l}\text { Lung Transplantation Using Hepatitis C Positive Donors to Hepatitis C } \\
\text { Negative Recipients: A Pilot Study (ClinicalTrials) }\end{array}$ & $\begin{array}{l}\text { University Health Network, } \\
\text { Toronto Gilead Sciences }\end{array}$ & 2017 & Not specified \\
\hline $\begin{array}{l}\text { Finding New Criteria for a Revised Primary Graft Dysfunction Score in } \\
\text { Lung Transplantation - a Pilot Study (ClinicalTrials) }\end{array}$ & $\begin{array}{l}\text { Medical University of Vienna, } \\
\text { Toronto General Hospital }\end{array}$ & 2017 & Not specified \\
\hline $\begin{array}{l}\text { Ex Vivo Lung Perfusion: Effect of Cellular Perfusate on Mechanical } \\
\text { Properties and Gas Exchange Function of Donor } \\
\text { Lungs(ClinicalTrials) }\end{array}$ & $\begin{array}{l}\text { Postgraduate Institute of Medical } \\
\text { Education and Research, India }\end{array}$ & 2016 & Not specified \\
\hline $\begin{array}{l}\text { Pharmacokinetics of Imipenem During Ex Vivo Lung Perfusion } \\
\text { (ClinicalTrials) }\end{array}$ & University of Turin, Italy & 2016 & Not specified \\
\hline $\begin{array}{l}\text { EVLP to Evaluate the Eligibility for Transplantation of DCD-Lungs } \\
\text { (ClinicalTrials) }\end{array}$ & Policlinico Hospital, Italy & 2014 & Not specified \\
\hline $\begin{array}{l}\text { Extending Preservation and Assessment Time of Donor Lungs Using } \\
\text { the Toronto EVLP System }{ }^{\mathrm{TM}} \text { at a Dedicated EVLP } \\
\text { Facility(ClinicalTrials) }\end{array}$ & $\begin{array}{l}\text { Lung Bioengineering Inc. } \\
\text { (including centers in USA) } \\
\text { (Phase 2) }\end{array}$ & 2014 & Toronto EVLP System ${ }^{\mathrm{TM}}$ \\
\hline $\begin{array}{l}\text { Use of Ex Vivo Lung Perfusion (EVLP) in Reconditioning Marginal } \\
\text { Donor Lungs for Transplantation (ClinicalTrials) }\end{array}$ & $\begin{array}{l}\text { Centre hospitalier de l'Université de } \\
\text { Montréa, Montreal, Quebec, } \\
\text { Canada }\end{array}$ & 2014 & Not specified \\
\hline $\begin{array}{l}\text { Rule of Carbone Monoxyde in the Ex Vivo Lung Perfusion } \\
\text { Reconditioning (ClinicalTrials) }\end{array}$ & $\begin{array}{l}\text { University Hospital of } \\
\text { Mont-Godinne, Belgium }\end{array}$ & 2014 & Not specified \\
\hline $\begin{array}{l}\text { Novel Lung Trial: Normothermic Ex Vivo Lung Perfusion As An } \\
\text { Assessment Of Extended/Marginal Donor Lungs (ClinicalTrials) }\end{array}$ & $\begin{array}{l}\text { XVIVO Perfusion (including } \\
\text { centers in USA) }\end{array}$ & 2011 & $\begin{array}{l}\text { XPSTM with Steen } \\
\text { Solution }^{\mathrm{TM}}\end{array}$ \\
\hline $\begin{array}{l}\text { Evaluation and Reconditioning of Marginal Lung Donors to } \\
\text { Transplantation by ex Vivo Lung Perfusion(ClinicalTrials) }\end{array}$ & $\begin{array}{l}\text { InCor Heart Institute, São Paulo, } \\
\text { Brazil }\end{array}$ & 2011 & Not specified \\
\hline
\end{tabular}

EVLP will be beneficial and valuable for all donor lungs, or will work as a tool to evaluate and recondition sub-optimal donor lungs. These two approaches might lead to diverged pathways: use EVLP to reduce comorbidities and increase the long-term survival, or expand the transplant organ pools, or could get both done under various conditions [128].

\section{EVLP-Based "Ready-to-Use" Organ Transplant Era Opening}

An organ reconditioning hub model aiming for disseminating EVLP to small and large transplant centers showed promise to increase lung utilization. New paradigm of organ preservation and evaluation will shape the organ allocation processes arising regulatory issues calls for more attention from all parts of stakeholders [129]. "Centralization of lungs on EVLP" guided PERFUSIX trial [clinical trial ID: NCT02234128] launched in the USA aims to construct an EVLP center to repair the rejected lungs and then shipped acceptable lungs to transplant centers. Further, centralizing the lungs from all available processes (including donation declined, autopsied) will expedite therapeutic discoveries on diseases and continuously monitored and data-sharing through cloud-based analyzing. Most importantly, financial burden of EVLP conduction which relies on special solutions or refined disposables is in need of reduction.

Advancement of EVLP translational research has involved multi-discipline teams, including transplantation, pulmonology, oncology, anesthesiology, intensive care thoracic surgery and rehabilitation, and ranking in topnotch research field in pulmonary medicine. Some obstacles brought by EVLP, such as immune- and infection-related 
inflammation balance, hypoxia and reperfusion injury, and metabolic abnormalities in lung microenvironment, are still unsolved but also provide opportunities to further explore update pathways of EVLP platform. More importantly, which should not be omitted, rodent models we used in frontier researches, having their inherent limitation when imitating human condition, such as lower perfusion flow in rat, are hypersensitive to perfusate. Thus we should find more efficient way to use declined human lungs [130] or lungs from cadavers for research upon overcoming the ethical barriers by organ procurement organizations with cross-border multi-center cooperation.

Acknowledgements Physicians of critical care, thoracic medicine, and members from Chinese lung transplantation alliance for discussion on the topics with insight are aknowledged.

\section{Compliance with Ethical Standards}

Conflict of Interest The author declares that there is no conflict of interest.

Ethical Approval This article does not contain any studies which need ethical approval performed by author.

Informed Consent This article does not contain any studies which need informed consent performed by author.

Statement of Animal Welfare This article does not contain any studies with animals performed by author.

Publisher's Note Springer Nature remains neutral with regard to jurisdictional claims in published maps and institutional affiliations.

\section{References}

1. Valapour M, Skeans MA, Smith JM, Edwards LB, Cherikh WS, Uccellini K, et al. OPTN/SRTR 2015 annual data report: lung. Am J Transplant. 2017;17(Suppl 1):357-424.

2. Makdisi G, Makdisi T, Jarmi T, Caldeira CC. Ex vivo lung perfusion review of a revolutionary technology. Ann Transl Med. 2017;5(17):343.

3. Tane S, Noda K, Shigemura N. Ex vivo lung perfusion: a key tool for translational science in the lungs. Chest. 2017;151(6):1220-8.

4. Martens A, Van Raemdonck DE, Smits J, et al. A retrospective database analysis to evaluate the potential of ex vivo lung perfusion to recruit declined lung donors. Transpl Int. 2017;30(10): 1002-10.

5. Chambers DC, Cherikh WS, Goldfarb SB, Hayes D Jr, Kucheryavaya AY, Toll AE, et al. The International Thoracic Organ Transplant Registry of the International Society for Heart and Lung Transplantation: thirty-fifth adult lung and heart-lung transplant report-2018; focus theme: multiorgan transplantation. J Heart Lung Transplant. 2018;37(10):1169-83.

6. Kakishita T, Oto T, Hori S, Miyoshi K, Otani S, Yamamoto S, et al. Suppression of inflammatory cytokines during ex vivo lung perfusion with an adsorbent membrane. Ann Thorac Surg. 2010;89:1773-9.
7. Jirsch DW, Fisk RL, Couves CM. Ex vivo evaluation of stored lungs. Ann Thorac Surg. 1970;10(2):163-8.

8. Hardesty RL, Griffith BP. Auto perfusion of the heart and lungs for preservation during distant procurement. J Thorac Cardiovasc Surg. 1987;93:11-8.

9. Steen S, Sjöberg T, Pierre L, Liao Q, Eriksson L, Algotsson L. Transplantation of lungs from a non-heart- beating donor. Lancet. 2001;357:825-9.

10. Steen S, Ingemansson R, Eriksson L, Pierre L, Algotsson L, Wierup P, et al. First human transplantation of a nonacceptable donor lung after reconditioning ex vivo. Ann Thorac Surg. 2007;83:2191-4.

11. Cypel M, Yeung JC, Liu M, Anraku M, Chen F, Karolak W, et al. Normothermic ex vivo lung perfusion in clinical lung transplantation. N Engl J Med. 2011;364:1431-40.

12. Rosso L, Zanella A, Righi I, Barilani M, Lazzari L, Scotti E, et al. Lung transplantation, ex-vivo reconditioning and regeneration: state of the art and perspectives. J Thorac Dis. 2018;10(Suppl 20):S2423-30.

13. Pan X, Yang J, Fu S, Zhao H. Application of ex vivo lung perfusion (EVLP) in lung transplantation. J Thorac Dis. 2018;10(7): 4637-42.

14. D'Cunha HC, Rojas M. Ex vivo lung perfusion: past, present, and future. ASAIO J. 2018;64(2):135-9.

15. Zhu B, Suzuki Y, DiSanto T, et al. Applications of out of body lung perfusion. Acad Radiol. 2018. https://doi.org/10.1016/j.acra. 2018.05.022.

16. Kotecha S, Hobson J, Fuller J, Paul E, Levvey BJ, Whitford H, et al. Continued successful evolution of extended criteria donor lungs for transplantation. Ann Thorac Surg. 2017;104(5):1702-9.

17. Boffini M, Ricci D, Bonato R, Fanelli V, Attisani M, Ribezzo M, et al. Incidence and severity of primary graft dysfunction after lung transplantation using rejected grafts reconditioned with ex vivo lung perfusion. Eur J Cardiothorac Surg. 2014;46(5):789-93.

18. Sage E, Mussot S, Trebbia G, Puyo P, Stern M, Dartevelle P, et al. Lung transplantation from initially rejected donors after ex vivo lung reconditioning: the French experience. Eur J Cardiothorac Surg. 2014;46(5):794-9.

19. Tikkanen JM, Cypel M, Machuca TN, Azad S, Binnie M, Chow $\mathrm{CW}$, et al. Functional outcomes and quality of life after normothermic ex vivo lung perfusion lung transplantation. J Heart Lung Transplant. 2015;34(4):547-56.

20. Wallinder A, Riise GC, Ricksten SE, Silverborn M, Dellgren G. Transplantation after ex vivo lung perfusion: a midterm follow-up. J Heart Lung Transplant. 2016;35(11):1303-10.

21. Luc JGY, Jackson K, Weinkauf JG, Freed DH, Nagendran J. Feasibility of lung transplantation from donation after circulatory death donors following portable ex vivo lung perfusion: a pilot study. Transplant Proc. 2017;49(8):1885-92.

22. Fisher A, Andreasson A, Chrysos A, Lally J, Mamasoula C, Exley $\mathrm{C}$, et al. An observational study of donor ex vivo lung perfusion in UK lung transplantation: DEVELOP-UK. Health Technol Assess. 2016;20(85):1-276.

23. Slama A, Schillab L, Barta M, Benedek A, Mitterbauer A, Hoetzenecker K, et al. Standard donor lung procurement with normothermic ex vivo lung perfusion: a prospective randomized clinical trial. J Heart Lung Transplant. 2017;36(7):744-53.

24. Yeung JC, Krueger T, Yasufuku K, de Perrot M, Pierre AF, Waddell TK, et al. Outcomes after transplantation of lungs preserved for more than $12 \mathrm{~h}$ : a retrospective study. Lancet Respir Med. 2017;5(2):119-24.

25. Nilsson T, Wallinder A, Henriksen I, Nilsson JC, Ricksten SE, Møller-Sørensen H, et al. Lung transplantation after ex vivo lung perfusion in two Scandinavian centres. Eur J Cardiothorac Surg. 2018. https://doi.org/10.1093/ejcts/ezy354. 
26. Henriksen IS, Møller-Sørensen H, Møller CH, et al. First Danish experience with ex vivo lung perfusion of donor lungs before transplantation. Dan Med J. 2014;61(3):A4809.

27. Abdalla LG, Braga KA, Nepomuceno NA, et al. Ex vivo lung perfusion in Brazil. J Bras Pneumol. 2016;42(2):95-8.

28. Schiavon M, Calabrese F, Di Gregorio G, et al. Ex-vivo recruitment and $\mathrm{x}$-ray assessment of donor lungs in a challenging retrieval from a donor supported by lvad using the portable normothermic perfusion system: a case report. J Cardiothorac Surg. 2017;12(1):30.

29. Sanchez PG, Mackowick KM, Kon ZN. Current state of ex-vivo lung perfusion. Curr Opin Organ Transplant. 2016;21(3):258-66.

30. Cypel M, Keshavjee S. The clinical potential of ex vivo lung perfusion. Expert Rev Respir Med. 2012;6(1):27-35.

31. Bassani GA, Lonati C, Brambilla D, Rapido F, Valenza F, Gatti S. Ex vivo lung perfusion in the rat: detailed procedure and videos. PLoS One. 2016;11(12):e0167898.

32. Zych B, Popov AF, Stavri G, Bashford A, Bahrami T, Amrani M, et al. Early outcomes of bilateral sequential single lung transplantation after ex-vivo lung evaluation and reconditioning. J Heart Lung Transplant. 2012;31(3):274-81.

33. Vallabhajosyula P, Korutla L, Habertheuer A, Reddy S, Schaufler $\mathrm{C}$, Lasky J, et al. Ex vivo lung perfusion model to study pulmonary tissue extracellular microvesicle profiles. Ann Thorac Surg. 2017:103(6):1758-66.

34. Broberg E, Wlosinska M, Algotsson L, et al. A new way of monitoring mechanical ventilation by measurement of particle flow from the airways using Pexa method in vivo and during ex vivo lung perfusion in DCD lung transplantation. Intensive Care Med Exp. 2018;6(1):18.

35. Okamoto T, Wheeler D, Liu Q, Quintini C, Hata JS, McCurry KR. Variability in pressure of arterial oxygen to fractional inspired oxygen concentration ratio during cellular ex vivo lung perfusion: implication for decision making. Transplantation. 2015;99(12):2504-13.

36. Okamoto T, Wheeler D, Liu Q, Quintini C, Hata JS, McCurry KR. Correlation between $\mathrm{PaO} 2 / \mathrm{FiO} 2$ and airway and vascular parameters in the assessment of cellular ex vivo lung perfusion system. J Heart Lung Transplant. 2016;35(11):1330-6.

37. Dromparis P, Aboelnazar NS, Wagner S, Himmat S, White CW, Hatami S, Luc JGY, Rotich S, Freed DH, Nagendran J, Mengel M, Adam BA Ex vivo perfusion induces a time- and perfusatedependent molecular repair response in explanted porcine lungs. Am J Transplant 2018

38. Egan T, Blackwell J, Birchard K, et al. Assessment of lungs for transplant recovered from uncontrolled donation after circulatory determination of death donors. Ann Am Thorac Soc. 2017;14(Supplement 3):S251.

39. Venkataraman A, Blackwell JW, Funkhouser WK, Birchard KR, Beamer SE, Simmons WT, et al. Beware cold agglutinins in organ donors! Ex vivo lung perfusion from an uncontrolled donation after circulatory-determination-of-death donor with a cold agglutinin: a case report. Transplant Proc. 2017;49(7):1678-81.

40. Medeiros IL, Pêgo-Fernandes PM, Mariani AW, Fernandes FG, do Vale Unterpertinger F, Canzian M, et al. Histologic and functional evaluation of lungs reconditioned by ex vivo lung perfusion. J Heart Lung Transplant. 2012;31(3):305-9.

41. Courtwright A, Cantu E. Evaluation and management of the potential lung donor. Clin Chest Med. 2017;38(4):751-9.

42. Motoyama H, Chen F, Hijiya K, Kondo T, Ohsumi A, Yamada T, et al. Plasmin administration during ex vivo lung perfusion ameliorates lung ischemia-reperfusion injury. J Heart Lung Transplant. 2014;33(10):1093-9.

43. Liersch-Nordqvist A, Fakhro M, Pierre L, et al. The impact of alteplase on pulmonary graft function in donation after circulatory death - an experimental study. Ann Med Surg (Lond). 2017;22:16.

44. Terragni PP, Fanelli V, Boffini M, Filippini C, Cappello P, Ricci D, et al. Ventilatory management during Normothermic ex vivo lung perfusion: effects on clinical outcomes. Transplantation. 2016;100(5):1128-35.

45. Spratt JR, Mattison LM, Iaizzo PA, Brown RZ, Helms H, Iles TL, et al. An experimental study of the recovery of injured porcine lungs with prolonged normothermic cellular ex vivo lung perfusion following donation after circulatory death. Transpl Int. 2017;30(9):932-44.

46. Maignan M, Gennai S, Debaty G, Romanini D, Schmidt MH, Brenckmann V, et al. Exhaled carbon monoxide is correlated with ischemia reperfusion injuries during ex vivo lung perfusion in pigs. J Breath Res. 2017;11(3):036004.

47. Yamada Y, Iskender I, Arni S, Hillinger S, Cosgun T, Yu K, et al. Ex vivo treatment with inhaled $\mathrm{N}$-acetylcysteine in porcine lung transplantation. J Surg Res. 2017;218:341-7.

48. Wang X, Parapanov R, Francioli C, Perentes JY, Letovanec I, Gonzalez M, et al. Experimental ex vivo lung perfusion with sevoflurane: effects on damaged donor lung grafts. Interact Cardiovasc Thorac Surg. 2018;26(6):977-84.

49. Lin H, Chen M, Tian F, Tikkanen J, Ding L, Andrew Cheung HY, et al. $\alpha 1$-anti-trypsin improves function of porcine donor lungs during ex-vivo lung perfusion. J Heart Lung Transplant. 2018;37(5):656-66.

50. Mordant P, Nakajima D, Kalaf R, Iskender I, Maahs L, Behrens P, et al. Mesenchymal stem cell treatment is associated with decreased perfusate concentration of interleukin- 8 during ex vivo perfusion of donor lungs after 18 -hour preservation. J Heart Lung Transplant. 2016;35(10):1245-54.

51. Becker S, Steinmeyer J, Avsar M, Höffler K, Salman J, Haverich A, et al. Evaluating acellular versus cellular perfusate composition during prolonged ex vivo lung perfusion after initial cold ischaemia for 24 hours. Transpl Int. 2016;29(1):88-97.

52. Hijiya K, Chen-Yoshikawa TF, Kondo T, Motoyama H, Ohsumi A, Nakajima D, et al. Bronchodilator inhalation during ex vivo lung perfusion improves posttransplant graft function after warm ischemia. Ann Thorac Surg. 2017;103(2):447-53.

53. Khalifé-Hocquemiller T, Sage E, Dorfmuller P, Mussot S, le Houérou D, Eddahibi S, et al. Exogenous surfactant attenuates lung injury from gastric-acid aspiration during ex vivo reconditioning in pigs. Transplantation. 2014;97(4):413-8.

54. Nakajima D, Liu M, Ohsumi A, Kalaf R, Iskender I, Hsin M, et al. Lung lavage and surfactant replacement during ex vivo lung perfusion for treatment of gastric acid aspiration-induced donor lung injury. J Heart Lung Transplant. 2017;36(5):577-85.

55. Inci I, Yamada Y, Hillinger S, Jungraithmayr W, Trinkwitz M, Weder W. Successful lung transplantation after donor lung reconditioning with urokinase in ex vivo lung perfusion system. Ann Thorac Surg. 2014;98(5):1837-8.

56. Motoyama H, Chen F, Hijiya K, Kondo T, Ohata K, Takahashi M, et al. Novel thermographic detection of regional malperfusion caused by a thrombosis during ex vivo lung perfusion. Interact Cardiovasc Thorac Surg. 2015;20(2):242-7.

57. Sage E, De Wolf J, Puyo P, et al. Real-time computed tomography highlights pulmonary parenchymal evolution during ex vivo lung reconditioning. Ann Thorac Surg. 2017;103(6):e535-7.

58. Renne J, Gutberlet M, Voskrebenzev A, et al. Functional pulmonary magnetic resonance imaging for detection of ischemic injury in a porcine ex-vivo lung perfusion system prior to transplantation. Acad Radiol. 2018;26(2):170-8.

59. Martens A, Ordies S, Vanaudenaerde BM, et al. A porcine ex vivo lung perfusion model with maximal argon exposure to attenuate ischemia-reperfusion injury. Med Gas Res. 2017;7(1):28-36. 
60. Cosgun T, Iskender I, Yamada Y, Arni S, Lipiski M, van Tilburg $\mathrm{K}$, et al. Ex vivo administration of trimetazidine improves posttransplant lung function in pig model. Eur J Cardiothorac Surg. 2017;52(1):171-7.

61. Shaghaghi H, Kadlecek S, Siddiqui S, Pourfathi M, Hamedani H, Clapp J, et al. Ascorbic acid prolongs the viability and stability of isolated perfused lungs: a mechanistic study using $31 \mathrm{P}$ and hyperpolarized $13 \mathrm{C}$ nuclear magnetic resonance. Free Radic Biol Med. 2015;89:62-71.

62. Kondo T, Chen F, Ohsumi A, Hijiya K, Motoyama H, Sowa T, et al. $\beta 2$-Adrenoreceptor agonist inhalation during ex vivo lung perfusion attenuates lung injury. Ann Thorac Surg. 2015;100(2): 480-6.

63. Stone ML, Zhao Y, Robert Smith J, Weiss ML, Kron IL, Laubach VE, et al. Mesenchymal stromal cell-derived extracellular vesicles attenuate lung ischemia-reperfusion injury and enhance reconditioning of donor lungs after circulatory death. Respir Res. 2017;18(1):212.

64. Andreasson AS, Karamanou DM, Gillespie CS, et al. Profiling inflammation and tissue injury markers in perfusate and bronchoalveolar lavage fluid during human ex vivo lung perfusion. Eur J Cardiothorac Surg. 2017;51(3):577-86.

65. Sommer W, Salman J, Avsar M, et al. Prediction of transplant outcome after 24-hour ex vivo lung perfusion using the Organ Care System in a porcine lung transplantation model. Am J Transplant. 2018. https://doi.org/10.1111/ajt.15075.

66. Himmat S, Alzamil A, Aboelnazar N, Hatami S, White C, Dromparis $\mathrm{P}$, et al. A decrease in hypoxic pulmonary vasoconstriction correlates with increased inflammation during extended normothermic ex vivo lung perfusion. Artif Organs. 2018;42(3):2719.

67. Hsin MK, Zamel R, Cypel M, Wishart D, Han B, Keshavjee S, et al. Metabolic profile of ex vivo lung perfusate yields biomarkers for lung transplant outcomes. Ann Surg. 2018;267(1):196-7.

68. Hashimoto K, Cypel M, Juvet S, et al. Higher M30 and high mobility group box 1 protein levels in ex vivo lung perfusate are associated with primary graft dysfunction after human lung transplantation. J Heart Lung Transplant. 2017. https://doi.org/10. 1016/j.healun.2017.06.005.

69. Hashimoto K, Cypel M, Kim H, Machuca TN, Nakajima D, Chen $\mathrm{M}$, et al. Soluble adhesion molecules during ex vivo lung perfusion are associated with posttransplant primary graft dysfunction. Am J Transplant. 2017;17(5):1396-404.

70. Machuca TN, Cypel M, Yeung JC, Bonato R, Zamel R, Chen M, et al. Protein expression profiling predicts graft performance in clinical ex vivo lung perfusion. Ann Surg. 2015;261(3):591-7.

71. Trebbia G, Sage E, Le Guen M, et al. Assessment of lung edema during ex-vivo lung perfusion by single transpulmonary thermodilution: a preliminary study in humans. J Heart Lung Transplant. 2018;38(1):83-91.

72. Cypel M, Keshavjee S. Extracorporeal lung perfusion (ex-vivo lung perfusion). Curr Opin Organ Transplant. 2016;21(3):329-35.

73. Weathington NM, Álvarez D, Sembrat J, et al. Ex vivo lung perfusion as a human platform for preclinical small molecule testing. JCI Insight. 2018;3(19). https://doi.org/10.1172/jci. insight.95515.

74. Hamid U, Krasnodembskaya A, Fitzgerald M, Shyamsundar M, Kissenpfennig A, Scott C, et al. Aspirin reduces lipopolysaccharide-induced pulmonary inflammation in human models of ARDS. Thorax. 2017;72(11):971-80.

75. Andreasson ASI, Borthwick LA, Gillespie C, Jiwa K, Scott J, Henderson $\mathrm{P}$, et al. The role of interleukin- $1 \beta$ as a predictive biomarker and potential therapeutic target during clinical ex vivo lung perfusion. J Heart Lung Transplant. 2017;36(9): 985-95.
76. Nakajima D, Cypel M, Bonato R, Machuca TN, Iskender I, Hashimoto K, et al. Ex vivo perfusion treatment of infection in human donor lungs. Am J Transplant. 2016;16(4):1229-37.

77. Zinne N, Krueger M, Hoeltig D, Tuemmler B, Boyle EC, Biancosino $\mathrm{C}$, et al. Treatment of infected lungs by ex vivo perfusion with high dose antibiotics and autotransplantation: a pilot study in pigs. PLoS One. 2018;13(3):e0193168.

78. Mehaffey JH, Charles EJ, Sharma AK, Salmon M, Money D, Schubert S, et al. Ex vivo lung perfusion rehabilitates sepsisinduced lung injury. Ann Thorac Surg. 2017;103(6):1723-9.

79. Machuca TN, Cypel M, Bonato R, Yeung JC, Chun YM, Juvet S, et al. Safety and efficacy of ex vivo donor lung adenoviral IL-10 gene therapy in a large animal lung transplant survival model. Hum Gene Ther. 2017;28(9):757-65.

80. Shafaghi S, Mortaz E, Abbasi Dezfuli A, et al. Normothermic ex vivo lung perfusion in brain-dead donors reduces inflammatory cytokines and toll-like receptor expression. Iran J Allergy Asthma Immunol. 2016;15(5):340-54.

81. Francioli C, Wang X, Parapanov R, Abdelnour E, Lugrin J, Gronchi F, et al. Pyrrolidine dithiocarbamate administered during ex-vivo lung perfusion promotes rehabilitation of injured donor rat lungs obtained after prolonged warm ischemia. PLoS One. 2017;12(3):e0173916.

82. Martens A, Boada M, Vanaudenaerde BM, Verleden SE, Vos $\mathrm{R}$, Verleden GM, et al. Steroids can reduce warm ischemic reperfusion injury in a porcine donation after circulatory death model with ex vivo lung perfusion evaluation. Transpl Int. 2016;29(11):1237-46.

83. Harada M, Oto T, Otani S, Miyoshi K, Okada M, Iga N, et al. A neutrophil elastase inhibitor improves lung function during ex vivo lung perfusion. Gen Thorac Cardiovasc Surg. 2015;63(12):645-51.

84. Luc JGY, Aboelnazar NS, Himmat S, Hatami S, Haromy A, Matsumura N, et al. A leukocyte filter does not provide further benefit during ex vivo lung perfusion. ASAIO J. 2017;63(5):6728.

85. Noda K, Tane S, Haam SJ, D'Cunha J, Hayanga AJ, Luketich JD, et al. Targeting circulating leukocytes and pyroptosis during ex vivo lung perfusion improves lung preservation. Transplantation. 2017;101(12):2841-284.

86. Stone JP, Sevenoaks H, Sjöberg T, et al. Mechanical removal of dendritic cell-generating non-classical monocytes via ex vivo lung perfusion. J Heart Lung Transplant. 2014;33(8):864-9.

87. Noda K, Tane S, Haam SJ, Hayanga AJ, D'Cunha J, Luketich JD, et al. Optimal ex vivo lung perfusion techniques with oxygenated perfusate. J Heart Lung Transplant. 2017;36(4):466-74.

88. Haam S, Lee JG, Paik HC, Park MS, Lim BJ. Hydrogen gas inhalation during ex vivo lung perfusion of donor lungs recovered after cardiac death. J Heart Lung Transplant. 2018;37(10):1271-8.

89. Haam S, Lee S, Paik HC, Park MS, Song JH, Lim BJ, et al. The effects of hydrogen gas inhalation during ex vivo lung perfusion on donor lungs obtained after cardiac death. Eur J Cardiothorac Surg. 2015;48(4):542-7.

90. Noda K, Shigemura N, Tanaka Y, Bhama J, D'Cunha J, Kobayashi $\mathrm{H}$, et al. Hydrogen preconditioning during ex vivo lung perfusion improves the quality of lung grafts in rats. Transplantation. 2014;98(5):499-506.

91. Yeung JC, Zamel R, Klement W, Bai XH, Machuca TN, Waddell $\mathrm{TK}$, et al. Towards donor lung recovery-gene expression changes during ex vivo lung perfusion of human lungs. Am J Transplant. 2018;18(6):1518-26.

92. Aboelnazar NS, Himmat S, Hatami S, White CW, Burhani MS, Dromparis $\mathrm{P}$, et al. Negative pressure ventilation decreases inflammation and lung edema during normothermic ex-vivo lung perfusion. J Heart Lung Transplant. 2018;37(4):520-30. 
93. Carnevale R, Biondi-Zoccai G, Peruzzi M, et al. New insights into the Steen solution properties: breakthrough in antioxidant effects via NOX2 downregulation. Oxidative Med Cell Longev. 2014;2014:242180.

94. Pagano F, Nocella C, Sciarretta S, Fianchini L, Siciliano C, Mangino G, et al. Cytoprotective and antioxidant effects of Steen solution on human lung spheroids and human endothelial cells. Am J Transplant. 2017;17(7):1885-94.

95. Lonati C, Bassani GA, Brambilla D, Leonardi P, Carlin A, Faversani A, et al. Influence of ex vivo perfusion on the biomolecular profile of rat lungs. FASEB J. 2018;32(10):5532-49.

96. Huerter ME, Sharma AK, Zhao Y, Charles EJ, Kron IL, Laubach VE. Attenuation of pulmonary ischemia- reperfusion injury by adenosine A2B receptor antagonism. Ann Thorac Surg. 2016;102(2):385-93.

97. Charles EJ, Mehaffey JH, Sharma AK, Zhao Y, Stoler MH, Isbell $\mathrm{JM}$, et al. Lungs donated after circulatory death and prolonged warm ischemia are transplanted successfully after enhanced ex vivo lung perfusion using adenosine $\mathrm{A} 2 \mathrm{~B}$ receptor antagonism. J Thorac Cardiovasc Surg. 2017;154(5):1811-20.

98. Andreasson A, Karamanou DM, Perry JD, Perry A, Özalp F, Butt $\mathrm{T}$, et al. The effect of ex vivo lung perfusion on microbial load in human donor lungs. J Heart Lung Transplant. 2014;33(9):910-6.

99. Mouraux S, Bernasconi E, Pattaroni C, et al. Airway microbiota signals anabolic and catabolic remodeling in the transplanted lung. J Allergy Clin Immunol. 2018;141(2):718-29 e7.

100. Pletcher SD, Goldberg AN, Cope EK. Loss of microbial niche specificity between the upper and lower airways in patients with cystic fibrosis. Laryngoscope. 2018. https://doi.org/10.1002/lary. 27454.

101. Becker J, Poroyko V, Bhorade S. The lung microbiome after lung transplantation. Expert Rev Respir Med. 2014;8(2):221-31.

102. Mitchell AB, Mourad B, Morgan LC, Oliver BGG, Glanville AR. Transplanting the pulmonary virome: dynamics of transient populations. J Heart Lung Transplant. 2018;37(9):1111-8.

103. Madan S, Mehra MR. The gut microbiome and transplantation: an amazon jungle. J Heart Lung Transplant. 2018;37(9):1043-4.

104. Cowan PJ, Hawthorne WJ, Nottle MB. Xenogeneic transplantation and tolerance in the era of CRISPR-Cas9. Curr Opin Organ Transplant. 2018;24(1):5-11.

105. Stone JP, Critchley WR, Major T, Rajan G, Risnes I, Scott H, et al. Altered immunogenicity of donor lungs via removal of passenger leukocytes using ex vivo lung perfusion. Am J Transplant. 2016;16(1):33-43.

106. Martens A, Ordies S, Vanaudenaerde BM, Verleden SE, Vos R, van Raemdonck DE, et al. Immunoregulatory effects of multipotent adult progenitor cells in a porcine ex vivo lung perfusion model. Stem Cell Res Ther. 2017;8(1):159.

107. Shah RJ, Diamond JM. Primary graft dysfunction (PGD) following lung transplantation. Semin Respir Crit Care Med. 2018;39(2): 148-54.

108. Martens A, Montoli M, Faggi G, Katz I, Pype J, Vanaudenaerde $\mathrm{BM}$, et al. Argon and xenon ventilation during prolonged ex vivo lung perfusion. J Surg Res. 2016;201(1):44-52.

109. Valenza F, Citerio G, Palleschi A, Vargiolu A, Fakhr BS, Confalonieri A, et al. Successful transplantation of lungs from an uncontrolled donor after circulatory death preserved in situ by alveolar recruitment maneuvers and assessed by ex vivo lung perfusion. Am J Transplant. 2016;16(4):1312-8.

110. Mehaffey JH, Charles EJ, Sharma AK, Money DT, Zhao Y, Stoler $\mathrm{MH}$, et al. Airway pressure release ventilation during ex vivo lung perfusion attenuates injury. J Thorac Cardiovasc Surg. 2017;153(1):197-204.

111. Linacre V, Cypel M, Machuca T, Nakajima D, Hashimoto K, Zamel R, et al. Importance of left atrial pressure during ex vivo lung perfusion. J Heart Lung Transplant. 2016;35(6):808-14.
112. Nilsson T, Gielis JF, Slama A, et al. Comparison of two strategies for ex vivo lung perfusion. J Heart Lung Transplant. 2017;36:S55.

113. Fernandes LM, Mariani AW, Medeiros IL, et al. Alternative solution for ex vivo lung perfusion, experimental study on donated human lungs non-accepted for transplantation. Acta Cir Bras. 2015;30(5):359-65.

114. Schumer EM, Zoeller KA, Linsky PL, Monreal G, Choi Y, Giridharan GA, et al. Feasibility study of pulsatile left ventricular assist device for prolonged ex vivo lung perfusion. Ann Thorac Surg. 2015;99(6):1961-7.

115. dos Santos PR, Iskender I, Machuca T, Hwang D, dePerrot M, Liu $\mathrm{M}$, et al. Modified in vivo lung perfusion allows for prolonged perfusion without acute lung injury. J Thorac Cardiovasc Surg. 2014;147(2):774-81.

116. Stanzi A, Neyrinck A, Somers J, Cauwenberghs H, Verbeken E, Santambrogio L, et al. Do we need to cool the lung graft after ex vivo lung perfusion? A preliminary study. J Surg Res. 2014;192(2):647-55.

117. Van De Wauwer C, Verschuuren EA, Nossent GD, et al. A staged approach for a lung-liver transplant patient using ex vivo reconditioned lungs first followed by an urgent liver transplantation. Transpl Int. 2015;28(1):129-33.

118. Palleschi A, Rosso L, Schiavon M, Rebusso A, Mendogni P, Rea F, et al. Is "lung repair centre" a possible answer to organ shortage?-transplantation of left and right lung at two different centres after ex vivo lung perfusion evaluation and repair: case report. J Thorac Dis. 2018;10(5):E318-21.

119. Luc JG, Nagendran J. The evolving potential for pediatric ex vivo lung perfusion. Pediatr Transplant. 2016;20(1):13-22.

120. Loor G. EVLP: ready for prime time? Semin Thorac Cardiovasc Surg. 2018. https://doi.org/10.1053/j.semtcvs.2018.05.005.

121. Van Raemdonck D, Rega F, Rex S, et al. Machine perfusion of thoracic organs. J Thorac Dis. 2018;10(Suppl 8):S910-23.

122. Mohite PN, Maunz O, Popov AF, Zych B, Patil NP, Simon AR. Utilization of the organ care system as ex-vivo lung perfusion after cold storagetransportation. Perfusion. 2015;30(8):698-700.

123. Ali F, Dua A, Cronin DC. Changing paradigms in organ preservation and resuscitation. Curr Opin Organ Transplant. 2015;20(2): $152-8$.

124. Schiavon M, Faggi G, Rebusso A, et al. Extended criteria donor lung reconditioning with the organ care system lung: a single institution experience. Transpl Int. 2018;32(2):131-40.

125. Loor G, Howard BT, Spratt JR, Mattison LM, PanoskaltsisMortari A, Brown RZ, et al. Prolonged EVLP using OCS lung: cellular and acellular perfusates. Transplantation. 2017;101(10): 2303-11.

126. Shafaghi S, Najafizadeh K, Sheikhy K, et al. The first experience of ex-vivo lung perfusion (EVLP) in Iran: an effective method to increase suitable lung for transplantation. Int J Organ Transplant Med. 2016;7(4):219-27.

127. Charles EJ, Huerter ME, Wagner CE, Sharma AK, Zhao Y, Stoler $\mathrm{MH}$, et al. Donation after circulatory death lungs transplantable up to six hours after ex vivo lung perfusion. Ann Thorac Surg. 2016;102(6):1845-53.

128. Levin K, Kotecha S, Westall G, et al. How can we improve the quality of transplantable lungs? Expert Rev Respir Med. 2016;3: $1-7$.

129. Yeung JC, Cypel M, Keshavjee S. Ex-vivo lung perfusion: the model for the organ reconditioning hub. Curr Opin Organ Transplant. 2017;22(3):287-9.

130. Zhang ZL, van Suylen V, van Zanden JE, et al. First experience with ex vivo lung perfusion for initially discarded donor lungs in the Netherlands: a single-centre study. Eur J Cardiothorac Surg. 2018. https://doi.org/10.1093/ejcts/ezy373. 